\title{
A ESPACIALIDADE ABERTA E RELACIONAL DO LAR: A ARTE DE CONCILIAR MATERNIDADE, TRABALHO DOMÉSTICO E REMOTO NA PANDEMIA DE COVID-19
}

\section{La espacialidad abierta y relacional del hogar: el arte de conciliar maternidad, trabajo doméstico y remoto en la pandemia de Covid-19}

\author{
Anita Loureiro de Oliveira \\ Geógrafa, Doutora em Planejamento Urbano, \\ Professora Associada do Departamento de Geografia da UFRRJ \\ Docente do quadro permanente do PPGGEO/UFRRJ \\ anitaloureiro@yahoo.com.br
}

Artigo enviado para publicação em 24/04/2020 e aceito em 29/04/2020

DOI: $10.12957 /$ tamoios.2020.50448

\begin{abstract}
Resumo
A reconhecida sobrecarga de trabalho acumulado pelas mulheres, especialmente as mães, e a intensificação do convívio familiar no contexto do isolamento social - proposto como ação de contenção da contaminação pelo Corona-vírus - motiva uma reflexão sobre a espacialidade e a densidade das relações domésticas. A ideia é refletir sobre esta espaço-temporalidade aberta e plural da maternidade, enfatizando as disputas de sentido que revelam o lar como espacialidade relacional e conflitiva. Cabe registrar o desafio do pensar/realizar a conciliação da maternagem e do trabalho doméstico, com as novas exigências de trabalho remoto, em meios às incertezas do presente. Trata-se de refletir a espacialidade cotidiana na visão da mulher-mãe que traz a maternagem para o debate teórico e político por acreditar que a "teoria" surge da vida e que o 'pessoal é político'. Pensar a casa, o lar, o espaço doméstico como espacialidade relacional e aberta é relevante para nossas pesquisas corporificadas e para os estudos das Geografias Feministas, que problematizam os desafios do trabalho intelectual das mães, especialmente em condições espaço-temporais adversas, como a do confinamento no lar em razão da pandemia.
\end{abstract}

\section{Palavras-chave}

Espacialidade; Maternidade; Trabalho doméstico; geografias feministas

\section{Resumen}

La reconocida sobrecarga de trabajo acumulada por las mujeres, especialmente las madres, y la intensificación de la vida familiar en el contexto del aislamiento social, propuesto como acción para contener la contaminación por coronavirus, motiva una reflexión sobre la espacialidad y la densidad de las relaciones domésticas. La idea es reflexionar sobre esta temporalidad espacial abierta y plural de la maternidad, enfatizando las disputas de significado que revelan el hogar como una espacialidad relacional y conflictiva. Es necesario registrarse el desafío de pensar/realizar la conciliación de la maternidad y el trabajo doméstico, con las nuevas demandas del trabajo remoto, en medio de las incertidumbres del presente. Se trata de reflejar la espacialidad diaria en la visión de la mujer-madre que lleva la maternidad al debate teórico y político por creer que la "teoría" surge de la vida y que lo "personal és político". Pensar el hogar, el espacio doméstico como espacialidad relacional y abierta es relevante para nuestra investigación corporificada y para los estudios de Geografías Feministas que problematizan los desafíos del trabajo intelectual de las madres, especialmente en condiciones adversas de espacio-tiempo, como el de encierro en nustras casas debido a la pandemia.

\section{Palabras clave}

Espacialidad; Maternidad; Trabajo doméstico; geografías feministas 


\section{Para ver o mundo com poesia, é preciso ter as crianças por nossas mestras}

Há um texto de Rubem Alves - a complicada arte de ver - que cita a obra "Odes Elementales", de Pablo Neruda e mais especificamente a "Ode à Cebola" e que os autores usam para falar de uma perturbação ocular comum entre os poetas: educar os olhos para que estes possam ver o mundo com poesia. Alves, no intuito de ampliar nossa visão, lembra que o mais estranho nisso é o fato dos olhos, de todos os órgãos dos sentidos, serem os de mais fácil compreensão científica, dada sua física ser idêntica à física óptica de uma máquina fotográfica, ainda que a física não possa dar conta da densidade expressa em uma fotografia. Quando Alves diz que "há muitas pessoas de visão perfeita que nada veem" e cita Alberto Caeiro, heterônimo de Fernando Pessoa para nos chamar a atenção de que o "ato de ver não é coisa natural. Precisa ser aprendido" e vai a Nietzsche para dizer que a primeira tarefa da educação é ensinar a ver, o cronista ressalta que a diferença, para ele, se encontra no lugar onde os olhos são guardados.

Se os olhos estão na caixa de ferramentas, eles são apenas ferramentas que
usamos por sua função prática. Com eles vemos objetos, sinais luminosos,
nomes de ruas - e ajustamos a nossa ação. O ver se subordina ao fazer. Isso é
necessário. Mas é muito pobre. Os olhos não gozam... Mas, quando os olhos
estão na caixa dos brinquedos, eles se transformam em órgãos de prazer:
brincam com o que veem, olham pelo prazer de olhar, querem fazer amor com
o mundo. Os olhos que moram na caixa de ferramentas são os olhos dos
adultos. Os olhos que moram na caixa dos brinquedos, das crianças. Para ter
olhos brincalhões, é preciso ter as crianças por nossas mestras (ALVES, 2004).

Se me proponho a escrever sobre o cotidiano em um momento tão tragicamente marcado por uma pandemia, em que parte significativa do mundo encontra-se em quarentena, colocando em prática uma outra espacialidade, em que o distanciamento social é uma medida para conter o avanço da propagação do Corona vírus (COVID-19), é porque concordo que a primeira função da educação é ensinar a ver. Mas como eu gostaria de estar próxima desse tipo de professora que, como diz Alves, dedica-se a "apontar os assombros que crescem nos desvãos da banalidade cotidiana", eu quero é ter meu filho - a criança mais próxima a mim - como mestre da arte de ver o mundo com poesia. Quero aproveitar esta escrita em "quarentena" para aprender com 'minha' criança a ter olhos brincalhões.

\section{Mulher-mãe e sujeita da pesquisa: no confinamento, refletir a espacialidade aberta} - Mãe, brinca comigo! (Francisco, 3 anos)

Não é fácil analisar o presente. Mais difícil ainda se torna quando vivê-lo é, em si, o desafio. A maior dificuldade poderia ser a complexidade analítica ligada à tarefa de interpretar um movimento do real que está em curso e que, por ser aberto e não experimentado antes, revela-se ainda mais incerto. Mesmo que nossa proposta de método encontre amparo em Henri Lefebvre (1991), para quem o pensamento deve estar em movimento para acompanhar o movimento próprio do real, e que a abordagem teóricoconceitual do tempo-espaço adote uma perspectiva relacional e aberta, o momento atual exige algo mais. Há uma diferença entre querer ficar em casa e precisar ficar nela por um tempo que não se sabe qual e quando o que está em risco é a própria vida. O imperativo da permanência, da não-mobilidade em um contexto de pandemia é lido como privilégio aos que podem "se dar ao luxo" de não sair e, ao mesmo tempo, é reconhecidamente exaustivo em termos emocionais quando não parece haver outra forma de evitar a 
propagação do vírus. E na minha memória de mãe, que tem um fillho pequeno pedindo para brincar - quando o trabalho (doméstico ou remoto) se acumula, quando se tem medo e insegurança da contaminação e muita incerteza do futuro -, sobram questões. Para além da perversa construção social da maternidade cercada de culpa, não há nada tão vivo e presente neste tempo (que parece suspender e cancelar ações de modo tão determinante) que o imperativo das crianças por brincar.

Falar em cuidado e saúde mental de crianças e mães parece pouco acadêmico? Pouco geográfico? Estando há algumas semanas vivendo o isolamento social proposto pelo decreto estadual publicado em março de $2020^{1}$, quando medidas de distanciamento foram adotadas, no âmbito da Administração Pública do Estado do Rio de Janeiro, para enfrentamento da emergência de saúde pública de importância internacional decorrente do corona-vírus, e considerando que a Pandemia de COVID-19 mudou a vida de crianças e famílias em todo o mundo, esforço-me em pensar o cotidiano doméstico de famílias que estão em suas casas com crianças. Para isso, é preciso ter sensibilidade analítica e exercitar a visão (com alguma poesia) e uma escuta atenta para reconhecer as consequências do fechamento de escolas e das restrições de movimento, que embora sejam considerados necessários, modificaram a rotina das crianças e impactam os sistemas de apoio e as práticas de cuidado de que dependem as famílias. A suspensão das aulas e o fechamento das escolas adicionou novas formas de estresse aos cuidadores e em muitos casos tornou este cuidado inconciliável com outros trabalhos.

De acordo com o IBGE (2016), no Brasil, em 2015, crianças e adolescentes correspondiam a $21,0 \%$ da população, conforme a Pesquisa Nacional por Amostra de Domicílios - PNAD 2015². Para as crianças, o cotidiano no confinamento exigido pela política de isolamento social trouxe problemas de vários tipos: o estresse de uma mudança brusca de rotina, a suspensão das brincadeiras nos espaços públicos - o parque, a praça e outras áreas comunitárias -, a restrição do movimento ao espaço da casa, diminuição da ludicidade corporal com a falta de convívio com outras crianças. Para piorar, as variadas formas de violência "doméstica" que incidem particularmente sobre crianças e mulheres fazem com que o tema do isolamento social nos leve a uma preocupação ainda maior quanto aos riscos ligados aos abusos, à negligência e à exploração infantil ${ }^{3}$.

Inspirando-me em bell hooks (2016), trato a violência ocorrida nos lares como "violência patriarcal". Para hooks, usar o termo patriarcal para falar desta violência no espaço doméstico seria

útil porque, diferentemente da expressão "violência doméstica", mais comum, ele constantemente lembra o ouvinte que a violência no lar está ligada ao sexismo e ao pensamento sexista, à dominação masculina. Por muito tempo, o termo violência doméstica tem sido usado como um termo "suave", que sugere emergir em um contexto íntimo que é privado e de alguma maneira menos ameaçador, menos brutal, do que a violência que acontece fora do lar. Isso não procede, já que mais mulheres são espancadas e assassinadas em casa do que fora dela (hooks, 2019, p.96. Grifos meus).

hooks (2019b) inspira uma geografia do lar como lugar da resistência e que se compromete com a transformação de estruturas opressoras de dominação seculares. A violência patriarcal se acentuou nesses tempos de pandemia, não apenas no Brasil, como em vários outros países. Os dados da Organização das Nações Unidas (ONU) são reveladores e é preciso visibilizar as recomendações deste e outros órgãos governamentais e supranacionais para a adoção de medidas que visam prevenir, proteger e mitigar as consequências das formas de violência, estigma e discriminação, especialmente aquelas contra mulheres e crianças durante processos de quarentena e procedimentos isolamento 
social $^{4}$. Essa realidade reforça a importância de pensarmos a casa, o lar, o espaço doméstico como uma espacialidade relevante em nossas pesquisas, especialmente como objeto de estudo das Geografias Feministas, descaracterizando a visão dominante do lar (como "doce lar") reproduzida pela geografia humanística - amparada na experiência do homem "universal", visto que o lar pode ser (e é) um lugar de opressão patriarcal para mulheres e crianças.

Lutar contra a perpetuação da violência patriarcal é uma forma de resistir e se opor a outras formas de dominação que se apoiam sistematicamente outras opressões, como de raça e classe, como hooks também nos inspira a pensar. Concordamos ainda com a autora quando esta afirma que "uma cultura de dominação é anti-amor. Exige violência para se sustentar. Escolher o amor é ir contra os valores predominantes dessa cultura".

\begin{abstract}
Sem uma ética do amor moldando a direção de nossa visão política e nossas aspirações radicais, muitas vezes somos seduzidas/os, de uma maneira ou de outra, para dentro de sistemas de dominação — imperialismo, sexismo, racismo, classismo. Sempre me intrigou que mulheres e homens que passam uma vida trabalhando para resistir e se opor a uma forma de dominação possam apoiar sistematicamente outras (hooks, 2006, p.1[246]).
\end{abstract}

Assim, é preciso considerar as múltiplas interseções de gênero, raça, classe, sexualidade que constituem a maternagem para compreender o sentido relacional e aberto da espacialidade que buscamos analisar. As mulheres são as principais responsáveis pelas atividades ligadas aos cuidados domésticos e familiares. No Brasil, em 2016, as mulheres dedicaram aos cuidados de pessoas e/ou afazeres domésticos cerca de $73 \%$ a mais de horas do que os homens (18,1 horas contra 10,5 horas) $)^{5}$.

Quando o foco são os cuidados com as crianças pequenas, a situação de sobrecarga das mulheres é ainda mais evidente. A PNAD 2015 estimou em cerca de 10,3 milhões o contingente de crianças de menos de 4 anos de idade no País, o que representava $5,1 \%$ da população residente. À época da pesquisa $83,7 \%$ das crianças de menos de 4 anos tinham uma mulher como primeira pessoa responsável por elas (IBGE, 2017) enquanto apenas $16,3 \%$ tinham homens como principal responsável. Dessas crianças, $46 \%$ estavam sob a responsabilidade de uma mulher 'não ocupada' e 37\% delas por mulheres ocupadas. No contexto da pandemia, preocupa o fato das mulheres estarem na base dos serviços considerados essenciais. Mulheres negras de baixa renda são as mais atingidas pela crise econômica e sanitária provocada pela pandemia porque estão na base do sistema de cuidados exigidos tanto pela saúde pública, como na vida privada. Trabalhadoras domésticas, funcionárias dos serviços de limpeza urbana e hospitalar, funções ligadas ao abastecimento, farmácias, supermercados, além de outros serviços essenciais como setores da saúde (cuidadoras de idosos, técnicas e assistentes hospitalares, enfermeiras e médicas). Nesses casos, as dificuldades são ainda maiores por terem que acumular funções, seguindo rotinas fora de casa, deixando seus/suas filhos/as dependentes da convivência com parentes ou pessoas próximas à família, colocando-as no risco de serem expostas às violências mencionadas anteriormente, somadas agora aos riscos de contaminação por Covid-19.

Sabe-se que nesse contexto de pandemia, os ataques aos direitos de pessoas precarizadas em suas relações de trabalho atingem diretamente as mulheres. 39\% dos empregadores de diaristas renunciaram ao serviço destas profissionais, sem, entretanto, manter o pagamento das diárias e isso é extremamente violento para as trabalhadoras domésticas, que no Brasil são cerca de 6,5 milhões, trabalhando para $11 \%$ das famílias brasileiras, que contam com o serviço de ao menos uma trabalhadora doméstica ${ }^{6}$. A violência nestes casos evidencia o recorte de gênero, raça e classe que expõem as 
mulheres negras e pobres (e, portanto, crianças por elas cuidadas) à morte. Daí porque se pode falar em uma política de morte contra mulheres, em especial negras e pobres e da relevância de reflexões acadêmica que denunciem o racismo cotidiano e institucionalizado no qual estamos imersos. Sem diaristas e empregadas, a parcela da classe média e alta que dispensou os serviços (e manteve o pagamento), ao fazer a faxina da própria casa teve a oportunidade de refletir sobre as relações de trabalho que sustentamos em uma cultura racista e machista.

Para Lélia Gonzales (1984, p.223) "o racismo se constitui como a sintomática que caracteriza a neurose cultural brasileira" e "sua articulação com o sexismo produz efeitos violentos sobre a mulher negra em particular". Mais do que isso, é nesse reconhecimento do papel central exercido pela mulher, como sujeita fundamental da vida social (inclusive econômica) que se justifica a escolha do tema da pesquisa. E a escolha das referências teóricas é parte desse reconhecimento. Reconhecer e valorizar a contribuição de Lélia Gonzalez e sua decisiva atuação contra o racismo ao longo de sua trajetória política e intelectual é um compromisso de uma ciência geográfica antirracista e antissexista.

É justamente pelo reconhecer a posição em que me encontro enquanto pesquisadora branca que ocupa lugar de privilégio na estrutura social da qual faço parte, que preciso me opor à precarização da vida de mulheres sem trabalho remunerado, que dependem de formas precárias de contratação, que se reinventam como pequenas e médias empreendedoras maternas, ou que são mal remuneradas em sub-empregos, e que, ainda assim, costumam ser responsabilizadas, mas não reconhecidas, pela maior parte do trabalho de reprodução social (as tarefas não remuneradas do cuidado doméstico).

Em um cenário de crescente instabilidade política, econômica e social, são mulheres que carregam os custos físicos e emocionais mais pesados. São também as que conectadas em redes de apoio mútuo e colaboração expressam a ação solidária e a resistência horizontal que sobrevive à pandemia. Segura a curva das mães é uma destas ações criadas para mapear mulheres mães em situação de vulnerabilidade causada ou agravada pela pandemia do coronavírus em todo o Brasil e que, por meio de uma campanha colaborativa, busca apoio emergencial para este grupo, formado por mulheres que cuidam de crianças, adolescentes, idosos e pessoas com deficiência ${ }^{7}$.

Dados da Pesquisa Nacional por Amostra de Domicílios (PNAD) Contínua, do IBGE, compilados pela consultoria IDados apontam que ter o primeiro filho tende a reduzir o salário em cerca de $24 \%$ e se a família crescer e o número de crianças chegar a três ou mais, a queda no rendimento é de quase $40 \%{ }^{8}$. A mesma reportagem indica outra pesquisa realizada pela consultoria LCA, também feita a partir de dados da PNAD, que aponta que as mulheres eram a maioria entre os desalentados, os trabalhadores que desistiram de procurar por um novo emprego (idem).

No caso de lares que têm um arranjo familiar monoparental feminino - as mãessolo - este desafio é ainda mais significativo. Sabemos que muitas dessas mães-solo, ao viverem a monoparentalidade, acabam tendo muitas dificuldades de seguir trabalhando sem uma rede de apoio, que varia muito a depender das condições socioeconômicas e culturais destas mulheres. A figura da mãe-solo, por si só é múltipla ${ }^{9}$, geraria muitas reflexões sobre o que estamos falando, pois ainda há muito a se refletir sobre esta diversidade de mulheres que por diferentes razões vivem a experiencia de parentalidade solo. Entretanto cabe aqui lembrar que as mães estão em evidência criando suas crianças sem que estas tenham a oportunidade de ter o pai em suas vidas em função dos altos índices de abandono paterno. Apesar do reconhecimento de paternidade ser um direito básico da criança, segundo o Conselho Nacional de Justiça, com base no Censo Escolar 2010, mais de cinco milhões de estudantes não tinham o nome do pai no documento de identidade (CNJ, 2015) ${ }^{10}$. 
A pandemia apenas escancara os desafios impostos às muitas mulheres mães que precisam trabalhar em jornadas duplas ou triplas. Para estas mulheres responsáveis pela renda familiar, a divisão sexual do trabalho, que já era desigual, tende a se agravar na quarentena. Mesmo no caso de pesquisadoras e cientistas, trabalhadoras privilegiadas em termos de garantia da renda frente à maior parcela das mulheres-mães, manter-se produtiva acadêmica-cientificamente sem comprometer a qualidade da maternagem é um desafio. Há estudos que apontam que a parentalidade ativa leva quase metade das novas mães $(43 \%)$ e quase um quarto dos novos pais $(23 \%)$ a renunciarem ao emprego em período integral depois do nascimento de filhos/as ${ }^{11}$. Alessandra Minello (2020), uma demógrafa social que estuda como as famílias gerenciam o trabalho doméstico e remunerado, focando em mulheres acadêmicas e profissionais, diz que agora, bem mais do que antes, sente como se fosse seu próprio objeto e lembrar que o maternal wall termo usado para referir-se aos obstáculos que limitam e segregam as mães que trabalham - estão em uso há mais de uma década ${ }^{12}$.

Falar da espacialidade materna e propor uma reflexão sobre o cotidiano de mães que tiveram a possibilidade de ficar em casa no período de isolamento social, para alcançar experiências espaço-temporais do "confinamento domiciliar" neste período de quarentena, levando em consideração a realidade de mães professoras-pesquisadoras, com apoio nas referências feministas que carrego, significa questionar a construção de uma "norma familiar", que produz determinadas experiências de maternagem e de como sentidos são disputados quando mulheres reivindicam o protagonismo em seus modos de maternar. Mas significa também tensionar as teorias dominantes no campo geográfico que tendem a colocar como menos importantes as subjetividades e os conflitos no espaço doméstico que está diretamente relacionado às condições de saúde mental (sofrimento, angústia, ansiedade) e bem-estar de mulheres e crianças $^{13}$.

\section{Maternar confinada no lar: vivendo a espacialidade relacional}

Com base nas geografias feministas, a reflexão que proponho sobre a espacialidade materna e o lar enquanto espaço aberto e relacional, precisa estar ancorada em uma temporalidade igualmente aberta e relacional como é o tempo desta quarentena. Tal como propõe Doreen Massey $(1999$, p.7) a "principal preocupação neste texto é com a questão de como podemos pensar o espaço - a espacialidade ${ }^{14}$ - hoje em dia, na nossa época e no contexto dos debates nos quais estamos envolvidos e dos desafios que estamos enfrentando". A autora nos instiga a pensar o espaço como necessariamente parte integrante e produto de inter-relações e interações, desde a imensidão do global até o intimamente pequeno, esfera na qual distintas trajetórias coexistem, e isto deve implicar na existência da pluralidade. Pensar o lar, o espaço doméstico enquanto este lugar de confinamento e abertura, estando numa temporalidade nova e aberta como a da quarentena (escrevo estas palavras no $40^{\circ}$ dia de confinamento e sem previsão de término, a se considerar o crescente número de óbitos e de contaminação) é algo que parece desafiar medos e inseguranças.

Para Massey, o espaço e a história são "abertos" e a compreensão do espaço como "aberto, não finalizado, sempre em devir" é como um pré-requisito essencial para a história ser aberta e, assim, um pré-requisito para a possibilidade da política (MASSEY, 1999, p.11). Pensar geograficamente a casa, o "lar", como recorte de análise é compreender o espaço doméstico como uma ambiência ainda mais complexa no cotidiano da pandemia. É em casa que temos que ficar. "Fique em casa", nos dizem as campanhas publicitárias em várias línguas. E aqui temos que estar para nos proteger e para garantir a diminuição da propagação do vírus, para diminuir o ritmo do contágio, para "baixar a 
curva". Agora, mais do que antes, o espaço doméstico é vivido (e refletido) mais intensamente com a família confinada em casa, ao mesmo tempo em que nossas ações continuam nos conectando com o mundo externo à casa. Tarefas domésticas de abastecimento (presenciais ou on line), o trabalho remoto ou à educação domiciliar das crianças, bem como outras práticas da rotina da mãe-trabalhadora, evidenciam que pensar nossa ação enquanto sujeita nos coloca fortemente em contato com o sentido aberto da espacialidade que estamos analisando.

Massey (2008, p. 250) se interessou pelas geometrias do poder e pelos termos em que a abertura e o fechamento se dão em tempos-espaços específicos e relata que um de seus projeto de pesquisa buscou refletir sobre "dois tipos diferentes de tempo-espaço: o laboratório científico e o lar”, que aparentemente levava a geógrafa a pensar sobre abertura global e autocontenção local, quando teve oportunidade de por meio de trabalhos de campo verificar que os lares de cientistas pesquisadores aparentemente abertos e relativamente porosos, continham no seu interior "lugares-dentro-de-lugares": "Era o escritório do papai, não se podia entrar lá” (MASSEY, 2008, p.253). Massey destaca que embora os laboratórios high-tech dos cientistas da área de pesquisa e desenvolvimento (P\&D) não fossem, definitivamente, "invadidos" pelo ambiente doméstico, "esses lares eram, certamente, invadidos por 'seu' trabalho" (2008, p.252). Construídos praticamente da mesma forma que os fechados laboratórios de P\&D, os 'escritórios do papai' no lar eram material e imaginativamente feitos como aqueles lugares especializados e assépticos da ciência e, portanto, "espaço da razão defendido contra contaminações do corpo" (MASSEY, 2008, p.252). A autora diz que "a pesquisa prosseguiu para investigar por que o tempo-espaço de um era tão "mais forte" do que o outro" e conclui afirmando que cada um desses tempo-espaços é relacional (idem: p.253). Cada um é construído pela articulação de trajetórias" e "cada tempo-espaço, também, está continuamente mudando em sua construção, sendo renegociado".

Em que lugar da casa a mulher-mãe pesquisadora vai ambientar seu "lugar-dentrodo-lugar", seu tempo-espaço do trabalho? Para escrever as linhas desse artigo, a pesquisadora que também é mãe, teve que se fechar no quarto feito escritório em uma adaptação para realizar o trabalho intelectual com o mínimo de silêncio e concentração que esta tarefa exige. Horas dedicadas ao trabalho e que são incompreensíveis para uma criança que tem a mãe tão perto e tão longe.

Não é novidade que a maternidade seja vista como obstáculo à carreira científica, e o isolamento social enquanto contenção do Corona-vírus parece simplesmente ter exacerbado essas desigualdades, eliminando o apoio que as mulheres possuíam para encarar mais essa desigualdade de gênero, que passa pelos cuidados com as crianças. Já há dados preliminares de importantes periódicos estrangeiros que sugerem que o COVID19 está prejudicando a produtividade das pesquisas das mulheres e reduzindo a participação de pesquisadoras no envio de artigos para revistas científicas ${ }^{15}$.

Tendo um filho de 3 anos e tendo que seguir produzindo intelectualmente, tenho me deparado com relatos de amigas e colegas que estão tendo muitas dificuldades com a nova rotina de confinamento e já aprecem notícias do impacto desta nova onda de exigências sobre a mulher, em especial as mães. Não são poucas as reportagens ou postagens em redes sociais com centenas de milhares de comentários e compartilhamentos - tratando do tema da exaustão materna na pandemia ${ }^{16}$. Por essa razão e essas emoções que o tema suscita, me interessa refletir sobre o cotidiano de mulheres que são responsáveis pelo cuidado de crianças, bem como de doentes e idosos/as, e que em isolamento social ficam ainda mais responsáveis pelo trabalho doméstico. Ainda que muitas vezes sejam responsáveis pelo sustendo de suas famílias, com um trabalho remunerado que agora precisa ser realizado em casa, professoras que são mães - em seus 
variados recortes de raça e classe -, sentem-se afetadas pelos rumos que a vida doméstica vem tomando nessa espaço-temporalidade da pandemia. A educação (domiciliar, à distância) soma-se a esta carga de preocupação que acaba por se agravar quando mães são também professoras.

Nessa ambiência criada pelo isolamento social, o lar é também "lugar-dentro-deoutro-lugar" de onde as novas formas e funções de trabalho remoto vão ter que "dividir espaço e tempo" com o cuidado e as tarefas domésticas (ampliadas pelo tempo de permanência da família em casa e que agora se somam às novas exigências de higienização e prevenção à contaminação por Covid-19). Estar ausente em presença é algo que exige das mulheres mães e crianças pequenas um esforço emocional adicional.

A proposta de pensar uma geografia existencial e corporificada pressupõe a valorização das diversas formas de existir e o reconhecimento de corpo-espacialidades diversas e em movimento (OLIVEIRA, 2019). A proposta é seguir fazendo uma geografia que explicite seu sentido existencial e que esteja aberta às questões de método propostas pelos estudos feministas de valorização dos saberes situados, corporificados, parciais, localizados, críticos, que articulam a política e a epistemologia, tal como nos inspira Haraway (1995) segue sendo aquilo que move o pensamento.

O teletrabalho (webconferencias, lives, mapeamentos e atualizações em tempo real), revelam que a desaceleração proposta nas primeiras semanas da quarentena, como algo positivo que poderíamos ganhar com o confinamento, a esta altura já não corresponde às expectativas. "Assim, exige-se que trabalhadores e consumidores ajustem-se às orientações comportamentais que satisfazem, basicamente, aos interesses das firmas" (RIBEIRO, 2009 p.28) e mais uma vez aceleramos a vida, com adições de "homeoffice", "homescholling" e outras práticas neocoloniais de aprisionamento às telas. Desse modo, naturalizam-se os "interesses que organizam as atividades econômicas, que são reificadas as necessidades sociais, permitindo que a lógica do lucro seja apresentada como a única forma legítima de racionalidade", inclusive para as explicações científicas que também "sofrem os efeitos desse predomínio, na medida em que as ciências sociais absorvem, pelo menos em parte, as orientações e os valores da racionalidade dominante" (idem).

Com maior intensidade, as ideologias apropriam-se de suportes técnicos com grande poder de penetração na organização da vida cotidiana (RIBEIRO, 2009, p.30) e sem a gente ter tempo para uma reação até a educação infantil passa a ser alvo do "controle remoto" dos algoritmos. E esses suportes técnicos pensados para outros tempos vão se adaptando às novas exigências do presente inesperado e se atualizam sem transformar a racionalidade dominante. Agora professoras se endividam para garantir que suas aulas à distância tenham melhor qualidade de luz e som, parcelam um celular numa compra on line e trocam seus dados pessoais por um app ou programa de edição de vídeo "gratuito". Não bastasse a mudança no modo de lecionar, agora novas formas de estresse foram adicionadas ao trabalho docente feito em casa, como ter que gravar aulas virtuais de madrugada enquanto as crianças dormem. Nada de novo no front da maternagem, mas sem dúvida uma oportunidade de ganhar adeptos aos olhos que veem o peso do funcionamento da rotina doméstica.

Mas, como nos diz Massey (1999), o espaço é, desde o início, parcela integrante da constituição das subjetividades políticas, e, assim, as relações e interações que se dão no espaço doméstico constituem esta subjetividade política da "maternagem" que está visivelmente aberta (em disputa) e em relação com o movimento do mundo. A espacialidade relacional desta maternagem mais ampla, complexa e real que disputa sentidos e construções sociais, é o que se pretende alcançar com esta geografia 
corporificada e sensível, que tem hoje, mais do que antes, "o lar enquanto lugar da resistência".

Massey me inspira a fazer esta "teoria" que surge da vida e a escrever mesclando "discussões teóricas abstratas com estórias do cotidiano e, algumas vezes, pessoais, bem com política" (MASSEY, 2008, p.16) evidenciando a relevância do papel social que nos é atribuído enquanto mães no espaço da casa, especialmente quando somos mães e exercemos uma atividade científico-intelectual como a docência. Isso significa problematizar a ênfase no aspecto temporal da subjetividade e tentar alcançar sua espacialidade.

Mulheres internalizam e reproduzem práticas discriminatórias e é preciso desnaturalizar a ideias das mulheres como principais cuidadoras. Mas não podemos esquecer que ainda são as mulheres que estão diretamente envolvidas com o cuidado das crianças e que é preciso encontrar caminhos para lidar com o sofrimento, a angústia e a morte em termos de pandemia ${ }^{17}$.

Silvia Federici (2019) ao tratar de trabalho doméstico, reprodução e luta feminista fala da importância de degenerificar o trabalho e de como se pode tentar alcançar a transição do trabalho afetivo do plano ontológico ao econômico. A autora nos lembra que para Spinoza (1955 apud FEDERICI, 2019), os "afetos" são modificações do corpo que aumentam ou diminuem sua capacidade de agir, e lembra que esse "afeto" não significa um sentimento de ternura ou amor, mas significa, antes, nossa capacidade de interação e de mover "trocas e encontros que supostamente expandem nossos poderes e demonstram a infinita produtividade de nosso ser, mas também o caráter transformador - e, portanto, já político - da vida cotidiana" (FEDERICI, 2019, p.338). O trabalho afetivo é, assim, o trabalho que produz ou manipula afetos, trazendo sentimento de alívio, bem-estar e satisfação e Federici cita as análises de Hochschild e Hardt e Negri para marcar diferenças entre o trabalho emocional remunerado e o uso instrumental das emoções de modo a evidenciar diferenças entre estas interpretações. A autora destaca que entre as acadêmicas feministas o conceito de trabalho afetivo

\footnotetext{
forneceu ferramenta analítica para investigar novas formas de exploração do trabalho - principalmente feminino -, assim como novos modos de subjetividade e projetualidade, estimulando pesquisas empíricas sobre as mudanças que o trabalho reprodutivo e seus sujeitos sofreram ao entrar na esfera pública/comercial (FEDERICI, 2019: 346).
}

Federici argumenta que somente quando pensamos no trabalho afetivo como trabalho reprodutivo em sua dupla e contraditória função, como reprodução dos seres humanos e como reprodução da força de trabalho, é que podemos imaginar formas de luta e recusa que fortalecem as pessoas que cuidamos, em vez de destruí-las. Isso ajuda a compreender também a recusa das mulheres em relação à exploração e chantagem emocional, que está no cerne do trabalho doméstico não remunerado e mesmo do trabalho de cuidado remunerado (FEDERICI, 2019). Ainda que a comercialização do trabalho reprodutivo - principalmente feminino - siga se concretizando na economia global, durante a pandemia e com as estratégias de isolamento social, esse trabalho (antes privatizado e terceirizado) tende a continuar sendo realizado pelas mulheres.

Para Federici (2019, p. 42) o trabalho doméstico não apenas foi imposto às mulheres, como foi transformado em um "atributo natural" da psique da personalidade feminina, que supostamente introjetaria "naturalmente" o fato dele não ser remunerado, dado que seria "uma aspiração, supostamente vinda das profundezas da nossa natureza feminina". Por sua vez, a condição não remunerada do trabalho doméstico realizado pelas mulheres tem sido a arma mais poderosa no fortalecimento do senso comum de que o 
trabalho doméstico não é trabalho, impedindo assim que as mulheres lutem contra ele, para além do que a autora chama de "querela privada do quarto-cozinha".

Assim, parece evidente que a espaço-temporalidade aberta e relacional do lar limitada por uma visão masculino-machista da geografia - foi pouco explorada enquanto lugar de confronto ideológico e político e, como tal, faz-se tema interessante à reflexão geográfica. As mulheres, especialmente as mães, precisam lutar cotidianamente para terem garantias do direito sobre seus próprios corpos e esta luta se dá também no lar e nas relações familiares. Reivindicar o direito de termos nosso próprio tempo-espaço, em meio às urgências domésticas e afetivas, é uma afirmação política das mães que pretendem se livrar das imposições que envolvem a maternidade. Esta afirmação política da espacialidade materna aberta extrapola o lar e impacta a forma como nos relacionamos com o mundo, o que, certamente, afeta nossos modos de geografar.

É exaustivo ter que encarar esse "desafio constante [de] mostrar que fazemos ciência e não só militância, e que as teorias feministas contribuem para ampliar o olhar geográfico" como afirmou Veleda em uma entrevista recentemente a Caroline Tapia Bueno e Diego Miranda Nunes (BUENO; NUNES, 2019, p.259). E é especialmente difícil disputar o sentido político da maternagem quando há que disputar sentidos tão básicos como aqueles que afirmam o direito de docentes-mães poderem fazer parte dos quadros permanentes dos programas de pós-graduação. É cansativo ter que disputar "espaços" de modo tão desigual em nosso próprio campo de atuação, como docentes e pesquisadoras da Geografia. Se "a geografia dos corpos maternos ainda não se apresenta enquanto debate facilmente encontrado" (CALABRIA, 2019, p. 100), é preciso permitir que isso aconteça. É urgente que possamos fazer nossas próprias geografias existenciais.

\section{Considerações finais}

Fazer uma geografia comprometida com a vida e com a densidade das ações corporificadas que afirmam o direito à existência plural é algo com o qual me comprometo. É preciso que a ciência geográfica seja questionada se as reflexões realizadas em nosso campo estão verdadeiramente comprometidas com políticas de igualdade plena. Se o acesso ao mundo do trabalho ainda é desigual e persistem nos imaginários geográficos e em nossas ações cotidianas as construções sociais do sistema patriarcal - racista e sexista -, isso precisa ser debatido. Essa geografia sensível e corporificada parece uma excelente oportunidade de abertura para a construção coletiva de uma vida renovada. Em meio a uma pandemia, e na correria de ser mãe e pesquisadora, não posso mais adiar aquilo que realmente importa: brincar com meu filho e aprender a ver o mundo com alguma poesia.

"A liberdade e a poesia a gente aprende com as crianças"

(Manoel de Barros)

\section{Notas}

1 - Decreto Estadual n 46966. Publicado no DOE - RJ em 13 mar 2020.

2 - Segundo o Estatuto da Criança e do Adolescente - ECA (Lei n. 8.069, de 13.07.1990), considera-se criança a pessoa com menos de 12 anos e adolescente a pessoa entre 12 e 18 anos de idade (BRASIL, 1990 apud IBGE: 2016, p.37). De acordo com o IBGE, em 2015, 17,6\% das crianças de 0 a 4 anos e $18,0 \%$ das crianças e adolescentes de 5 a 14 anos residiam em domicílios cujo rendimento mensal per capita era de até $1 / 4$ do salário mínimo. Crianças e adolescentes são ainda os que mais vivem em situação de insegurança alimentar, como se constatou por meio do Suplemento de Segurança Alimentar da PNAD 2013 (IBGE: 2016, p.39). 
3 - Tal como ressaltam os comunicados do UNICEF sobre o tema da violência doméstica, as crianças estão no centro das variadas formas de violência, abuso e exploração e ainda mais vulneráveis durante a quarentena e o isolamento social. Disponível em: https://www.unicef.org/brazil/comunicados-deimprensa/covid-19-criancas-em-risco-aumentado-de-abuso-negligencia-exploracao Acessado em 22 de abril de 2020

4 - A ONU recomenda aumentar o investimento em serviços online e organizações da sociedade civil; garantir que os sistemas judiciais continuem processando os agressores; estabelecer sistemas de alerta de emergência em farmácias e mercados. Também recomenda declarar abrigos como serviços essenciais; criar maneiras seguras para as mulheres procurarem apoio, sem alertar seus agressores; evitar libertar prisioneiros condenados por violência contra mulheres; ampliar campanhas de conscientização pública, principalmente as voltadas para homens e meninos. https://nacoesunidas.org/chefe-da-onu-alerta-paraaumento-da-violencia-domestica-em-meio-a-pandemia-do-coronavirus/Acessado em 22 de abril de 2020. 5 - "Ao desagregar por região, verifica-se que a maior desigualdade na distribuição de horas dedicadas a estas atividades está na Região Nordeste, onde as mulheres dedicam cerca de $80 \%$ a mais de horas do que os homens, alcançando 19 horas semanais. O recorte por cor ou raça indica que as mulheres pretas ou pardas são as que mais se dedicam aos cuidados de pessoas e/ou aos afazeres domésticos, com o registro de 18,6 horas semanais em 2016. Observa-se que o indicador pouco varia para os homens quando se considera a cor ou raça ou região de residência" (IBGE, 2018, p. 3).

6 - A pesquisa indica também que 23\% dos empregadores de diaristas e 39\% dos patrões de mensalistas afirmaram que suas funcionárias continuam trabalhando normalmente, mesmo durante o período de quarentena. $\quad$ https://agenciabrasil.ebc.com.br/economia/noticia/2020-04/covid-19-39-dos-patroesdispensaram-diaristas-sem-manter-o-pagamento Acessado em 22 de abril de 2020

7 - O "Instituto Casa Mãe" e o "Coletivo Massa" criaram o projeto "Segura a Curva das Mães" para priorizar mães e crianças no recebimento de ajuda emergencial durante a pandemia do Coronavírus. Disponível em https:/apoiomutuo.com.br/covid-19/segura-a-curva-das-maes-instituto-casa-mae-sao-paulo-sp/ Acessado em 24 de abril de 2020.

8 - GAVRAS Douglas, BRANDÃO Raquel. No Brasil, mãe recebe até 40\% menos. O Estado de São Paulo. 11 de dezembro de 2018. https://economia.estadao.com.br/noticias/geral,no-brasil-mae-recebe-ate-40menos, 70002641028 Acessado em 22 de abril de 2020

9 - No termo mães-solo cabem múltiplas existências, pois cada pessoa tem sua própria história e, assim, as mães-solo podem ser solteiras, casadas, separadas, viúvas, maternar por opção ou não, por adoção, inseminação "artificial" e de muitas outras formas. Mães-solo evidenciam as interseccionalidades (gênero, raça, classe, sexualidade) e, principalmente, os impactos do não reconhecimento paterno. O "solo", reivindicado por essas mães tem um sentido múltiplo de referir-se simultaneamente ao estar só na parentalidade, mas também de ser base, "chão" da criança de quem é responsável pelo cuidado.

10 - CONSELHO NACIONAL DE JUSTIÇA. Programa Pai Presente e Certidões. $2^{\mathrm{a}}$ edição 2015. Disponível em: https://www.cnj.jus.br/wpcontent/uploads/conteudo/destaques/arquivo/2015/04/b550153d316d6948b61dfbf7c07f13ea.pdf

Acessado em 24 de abril de 2020.

11 - Dados da Proceedings of the National Academy of Sciences PNAS, uma das revistas científicas multidisciplinares mais citadas e abrangentes do mundo, indicam que mulheres ainda estão subrepresentadas nos trabalhos de ciência, tecnologia, engenharia e matemática (STEM), mas que a impressionante taxa de $43 \%$ de mulheres contra $23 \%$ de homens que passam a trabalhar meio período ou deixam o trabalho ao tornarem-se mães/pais, evidencia diferenças substanciais de gênero com pouca variação por disciplina, raça e outros fatores demográficos. CECH \& BLAIR - LOY. The changing carreer trajectories of the new parentes in STEM. PNAS 116: 41824187. Disponível em https://www.pnas.org/content/116/10/4182 Acessado em 23 de abril de 2020.

12 - Sobre o 'muro materno' e outros desafios enfrentados pelas pesquisadoras durante o isolamento social ver: MINELLO, Alessandra. A pandemia e a mulher acadêmica. Vista Mundial. 17 de abril de 2020. Acessado em 23 de abril de 2020

13 - Com sua inestimável contribuição ao debate, Joseli Maria silva (2010) desvela as relações de poder inerentes à produção do conhecimento geográfico e denuncia a hegemonia androcêntrica que é inerente à invisibilidade feminina em nosso campo de conhecimento.

14 - "Estes termos serão usados de forma intercambiável neste artigo" (MASSEY, 1999, p. 7).

15 - Uma análise preliminar divulgada no site Inside Higher Education (link abaixo), editores de revistas científicas detectaram que mulheres estão submetendo menos artigos desde o início da pandemia. Ver mais em: FLAHERTY, Colleen. No Room of One's Own. Early journal submission data suggest COVID-19 is tanking women's research productivity. Inside Higher Education. April 21, 2020 Disponível em: https://www.insidehighered.com/news/2020/04/21/early-journal-submission-data-suggest-covid-19tanking-womens-research- 
productivity?fbclid=IwAR3rWNvXJTBFS1NTqr2jeRMQCAV2MvIEAAe3tkH8hL5pwYnBpiL7tmVFnp w . Acessado em 23 de abril de 2020

16 - Há numerosos registros em redes sociais deste sentimento compartilhado. Há perfis nas redes socais de mulheres que agregam milhares de "seguidoras" (falo aqui de perfis como "Cientista que virou mãe, política é a mãe, @a_maesolo, Maternidade e cuidado de si, entre muitas outras) que tratam desta militância pelo direito à maternagem crítica e sem culpa.

17 - A insatisfação de mães e pais com a educação à distância descolada da realidade da pandemia ganha reportagens e colunas na mídia e diante do questionamento das família, escolas seguem tentando aplicar práticas de educação domiciliar sem garantir que as crianças e professores/as que muitas vezes estão em moradias pequenas, inadequadas, ou não dispõem de equipamentos, redes de acesso à internet sejam incluídos/as. Os depoimentos ressaltam a importância de considerarmos o despreparo das escolas (docentes, diretores/as e proprietários/as) para lidar com o cotidiano, já que estamos falando de crianças e jovens que vão perder familiares e que, de um modo geral, escolas e família não têm focado suas ações no sentido de ter uma preocupação com o compartilhamento de ferramentas emocionais para professores, estudantes e cuidadores/as. Disponível em: https://www1.folha.uol.com.br/educacao/2020/04/maes-defendemsuspensao-do-calendario-de-escolas-durante-crise-do-coronavirus.shtml?fbclid=IwAR3PvaS3txTVSaDVFVaBw155w0X7DWTawEZa4PzNwyPVXAcv-vPXrrv61A Acessado em 22 de abril de 2020.

\section{Referências bibliográficas}

ALVES, Rubem. A complicada arte de ver. Folha de São Paulo, 20.10.2004. Disponível em https://www1.folha.uol.com.br/folha/sinapse/ult1063u947.shtml

BARROS, Manoel de. Exercícios de ser criança. São Paulo: Salamandra, 1999.

BUENO, Caroline Tapia; NUNES, Diego Miranda. Geografias Feministas: Relações de Gênero Patriarcais: Uma Entrevista com Susana Maria Veleda da Silva. Revista LatinoAmericana de Geografia e Gênero, v. 10, n. 1, p. 256-264, 2019.

CALABRIA, Roberta. Corpos grávidos: sobre o sistema imagético e a performatividade na ocupação do espaço. In. Actas IV Seminario Latinoamericano de Geografía, Género y Sexualidades / compilado por Diana Lan. - 1a ed . - Tandil : Universidad Nacional del Centro de la Provincia de Buenos Aires, 2019. Libro digital, PDF Disponível em https://b6e5df74-b898-4310-af42-

fc36af401bd1.filesusr.com/ugd/5772d5_659c5d929d4643e086fa8a0df4e0c459.pdf

CONSELHO NACIONAL DE JUSTIÇA. Programa Pai Presente e Certidões. $2^{\mathrm{a}}$ edição 2015. Disponível em: https://www.cnj.jus.br/wpcontent/uploads/conteudo/destaques/arquivo/2015/04/b550153d316d6948b61dfbf7c07f 13ea.pdf . Acessado em 24 de abril de 2020.

FEDERICI, Silvia. O ponto zero da revolução: trabalho doméstico, reprodução e luta feminista. Tradução Coletivo Sycorax. São Paulo : Elefante, 2019, 388p..

GONZALES Lélia. Racismo e sexismo na cultura brasileira. In: Revista Ciências Sociais Hoje, Anpocs, 1984, p. 223-244

HARAWAY, Donna. Saberes Localizados: a questão da ciência para o feminismo e o privilégio da perspectiva parcial. Cadernos Pagu, n.5, p.7-41, 1995.

hooks, bell. Ofeminismo é para todo mundo: políticas arrebatedoras. Tradução Ana Luiza Libânio - $3^{\text {a }}$ edição. Rio de Janeiro: Rosa dos Tempos, 2019, 176p.

"Lar: um lugar da resistência". In. hooks, bell. Anseios: raça, gênero e políticas culturais. São Paulo : Elefante, 2019b.

Love as the practice of freedom. In: Outlaw Culture. Resisting Representations. Tradução para uso didático por Wanderson Flor do Nascimento. Nova Iorque: Routledge, 2006, p. 243-250.

IBGE, Coordenação de Trabalho e Rendimento. Aspectos dos cuidados das crianças de menos de 4 anos de idade: 2015. - Rio de Janeiro : IBGE, 2017. 62p. https://biblioteca.ibge.gov.br/visualizacao/livros/liv100137.pdf 
IBGE, Coordenação de População e Indicadores Sociais. Estatísticas de gênero: indicadores sociais das mulheres no Brasil. Rio de Janeiro. n.38, 2018. https://biblioteca.ibge.gov.br/visualizacao/livros/liv101551_informativo.pdf

IBGE, Coordenação de População e Indicadores Sociais. Síntese de indicadores sociais: uma análise das condições de vida da população brasileira: 2016 / - Rio de Janeiro : IBGE, 2016146 p. https://biblioteca.ibge.gov.br/visualizacao/livros/liv98965.pdf

LEFEBVRE, Henri. Lógica formal lógica dialética. Tradução de Carlos Nelson Coutinho. Rio de Janeiro: Civilização Brasileira, 1991. $5^{\text {a }}$ edição [1969].

MASSEY, Doreen. Filosofia e Política da Espacialidade: Algumas Considerações. $\begin{array}{lllll}\text { GEOgraphia. } & \text { Ano. } & 6 & \text { V.12, }\end{array}$ http://periodicos.uff.br/geographia/article/view/13477/8677

Pelo espaço: uma nova política da espacialidade. Tradução Rogério Haesbaert. Rio de Janeiro: Bertrand Brasil, 2008. 312p.

SILVA, Joseli Maria. Geografias feministas, sexualidades e corporalidades: desafios às práticas investigativas da ciência geográfica. Espaço e Cultura (UERJ), v. 27, p. 39-55, 2010.

RIBEIRO, Ana Clara Torres. Presentificação, impulsos globais e espaço urbano. O novo economicismo. Otro desarrollo urbano: ciudad incluyente, justicia social y gestión democrática. En: Buenos Aires Lugar CLACSO Editorial/Editor, 2009 